\title{
Técnica da entrevista discursiva em pesquisa qualitativa: relato de experiência*
}

Discursive interview technique in qualitative research: experience report

Técnica de entrevista discursiva en investigación cualitativa: informe de experiencia

\section{Vanessa Rodrigues Pucci', Roberta Antunes Machado ${ }^{\mathrm{II}}$, Mario Cardano ${ }^{\mathrm{III}}$, Luciane Prado Kantorski $^{\mathrm{IV}}$, Teresinha Heck Weiller ${ }^{\mathrm{V}}$}

\begin{abstract}
Resumo: Objetivo: descrever uma experiência de estudo, reflexão e prática de realização da entrevista discursiva. Método: consiste num relato de experiência sobre o desenvolvimento e prática da técnica de entrevista discursiva, realizada entre setembro e dezembro de 2019, durante a disciplina de Metodi Qualitativi per la ricerca sociale, na Università degli Studi di Torino, na Itália. Foram aplicadas três entrevistas discursivas aos integrantes de uma associação ítalo-brasileira, utilizando uma amostragem valanga (técnica da bola de neve). Resultados: apresentam as etapas que antecedem a realização da entrevista discursiva, como o contato com o campo de pesquisa e com o tema que foi pesquisado, a elaboração do roteiro para entrevista, sua execução e sua transcrição. Conclusão: a entrevista discursiva é uma técnica que permite a compreensão da ação dos participantes e do seu contexto social. Por não aplicar questões predeterminadas, valoriza o que emerge no processo de integração.
\end{abstract}

Descritores: Entrevista; Pesquisa qualitativa; Metodologia; Discursos; Enfermagem

Abstract: Objective: to describe an experience of study, reflection and practice of conducting the discursive interview. Method: experience report on the development and practice of the discursive interview technique, carried out between September and December 2019, during the discipline of Metodi Qualitativi per la ricerca sociale, at the Università degli Studi di Torino, in Italy. Three discursive interviews were applied to the members of an Italian-Brazilian association, using a valanga sampling (snowball technique). Results: the steps that precede the

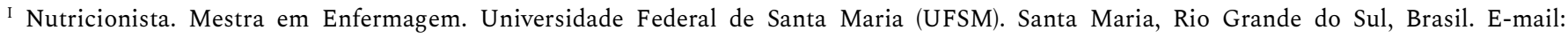
vanessarpucci@hotmail.com. ORCID https://orcid.org/0000-0002-4036-316X

II Enfermeira. Mestra em Ciências. Instituto Federal de Educação, Ciência e Tecnologia do Rio Grande do Sul (IFRS). Rio Grande, Rio Grande do Sul, Brasil. E-mail: roberta.machado@riogrande.ifrs.edu.br. ORCID https://orcid.org/0000-0002-9087-6457

III Filosofia. Doutor em Sociologia e Pesquisa Social. Università degli Studi di Torino (UniTo). Torino, Piemonte, Itália. E-mail: mario.cardano@unito.it. ORCID https://orcid.org/0000-0003-0268-3020

IV Enfermeira. Doutora em Enfermagem. Universidade Federal de Pelotas (UFPEL). Pelotas, Rio Grande do Sul, Brasil. E-mail: kantorski@uol.com.br. ORCID https://orcid.org/0000-0001-9726-3162

V Enfermeira. Doutora em Enfermagem e Saúde Pública. Universidade Federal de Santa Maria (UFSM). Santa Maria, Rio Grande do Sul, Brasil. E-mail: weiller2@hotmail.com. ORCID https://orcid.org/0000-0003-2531-0155
}

* Programa de Pós-Graduação em Sociologia, Departamento de Culturas, Política e Sociedade. Universidade de Torino (UniTo), Itália, 2019. 
discursive interview were presented, such as contact with the research field and with the theme that was researched, the elaboration of the interview guide, its execution and its transcription. Conclusion: the discursive interview is a technique that allows the understanding of the action of the participants and their social context. By not applying predetermined questions, it values what emerges in the integration process.

Descriptors: Interview; Qualitative research; Methodology; Address; Nursing

Resumen: Objetivo: describir una experiencia de estudio, reflexión y práctica de realización de la entrevista discursiva. Método: consiste en un informe de experiencia sobre el desarrollo y la práctica de la técnica de entrevista discursiva, realizado entre septiembre y diciembre de 2019, durante la disciplina de Metodi Qualitativi per la ricerca sociale, en la Università degli Studi di Torino, en Italia. Se aplicaron tres entrevistas discursivas a los miembros de una asociación ítalo-brasileña, utilizando un muestreo valanga (técnica bola de nieve). Resultados: presentan los pasos que preceden a la entrevista discursiva, como el contacto con el campo de la investigación y con el tema que se investigó, la elaboración de la guía para la entrevista, su ejecución y su transcripción. Conclusión: la entrevista discursiva es una técnica que permite comprender la acción de los participantes y su contexto social. Al no aplicar preguntas predeterminadas, valora lo que surge en el proceso de integración.

Descriptores: Entrevista; Investigación cualitativa; Metodología; Discurso; Enfermería

\section{Introdução}

Este texto procura abordar a entrevista discursiva, com suas potencialidades e limites, enquanto técnica de coleta de dados da pesquisa qualitativa, partindo do contexto de uma experiência vivenciada na Universidade de Turim, na Itália, na região de Piemonte. Inicia-se a imersão neste contexto a partir do resgate do conceito de pesquisa qualitativa e da entrevista discursiva para na sequência apresentar em detalhes a experiência.

Este tipo de investigação pode ser comparada a um arquipélago ${ }^{1-2}$ composto por várias ilhas distintas unidas por três traços metodológicos fortes: a utilização de uma forma de observação mais próxima do objeto de estudo; sensibilidade ao contexto, conferida pela harmonização das técnicas e as características daquilo que se deseja estudar; e a multivocalidade de escrita. ${ }^{3}$ É necessário considerar que são diversificados os referenciais teóricos para realização de estudos qualitativos, como o interacionismo, a fenomenologia, a etnometodologia e a sociolinguística. No entanto, a representação dos fenômenos sociais, como processuais e contingentes, requer uma adaptação das técnicas de pesquisa ao contexto em 
estudo. Esta harmonização dos procedimentos metodológicos ao objeto de estudo reforça a prioridade do objeto sobre o método. ${ }^{4}$

A palavra "qualitativa" remete à ênfase na qualidade dos processos, à natureza socialmente estruturada da realidade, à relação íntima entre pesquisador e o que é estudado, à busca de ações que valorizem a experiência, o significado. Deste modo, a pesquisa qualitativa é um campo de investigação, um complexo interconectado de famílias de termos, conceitos, abordagens teóricas que historicamente assumiram a tarefa de compreender a conduta em pauta e os processos sociais..$^{5-6}$

Compreende-se sua importância para estudar os fenômenos sociais devido à pluralização das esferas da vida, com uma diversidade de ambientes, subculturas, formas e estilos de vida, que exigem uma nova sensibilidade para realização de pesquisas. ${ }^{7}$ Desta forma, configura-se no campo da descrição e compreensão dos significados e processos subjetivos, conferidos às práticas e às experiências quotidianas, de maneira profunda e completa, em uma lógica de descoberta, de modo que o foco centra-se nas perspectivas dos atores, atendendo aos seus contextos particulares, e assim interpretando os fenômenos no seu meio natural. ${ }^{7-8}$

Ao se dedicar ao estudo dos fenômenos sociais, a pesquisa qualitativa lança mão de instrumentos, dentre os quais se destacam a entrevista discursiva, a observação aproximada e a observação naturalística como o shadowing (a observação de uma interação social em que o pesquisador segue o sujeito como uma sombra). ${ }^{1-2}$ No caso do primeiro instrumento, reforça-se que ele designa um tipo de relação social, em que o diálogo entre entrevistado e entrevistador se constitui em um jogo de sociabilidade. Para a sua realização, o roteiro, a condução e a transcrição são etapas distintas, mas que devem estar em sincronia. ${ }^{1-2}$

A entrevista discursiva é um instrumento de escavação utilizada por um amplo grupo de cientistas sociais. ${ }^{3-9}$ É uma forma de conversação que tem como característica o fato de que os conteúdos, as questões e o modo como são articuladas as respostas no diálogo não são 
predeterminadas e se definem, a cada momento, ao longo da interação entre entrevistado e entrevistador. ${ }^{1-2}$ Portanto, sob a forma de perguntas adequadas, em razão da evolução da conversa, o entrevistador solicitará a produção de respostas que lhe interessa, ou seja, sua intenção em obter aquelas que são pertinentes para atender os seus objetivos. ${ }^{1}$

Ademais, tal técnica proporciona a chance de se examinar importantes questões metodológicas e epistemológicas que deverão ser confrontadas por pesquisadores que lançarão mão da pesquisa qualitativa em seus estudos. ${ }^{2}$ Ressalta-se a potencialidade deste instrumento em representar experiências e interpretações dos indivíduos sobre suas realidades, e no nível de complexidade que se apresentam. ${ }^{10}$

A entrevista discursiva permite que o pesquisador faça uma imersão sobre o seu objeto de estudo, inclusive coletando sinais ou indícios de como os entrevistados percebem e significam sua realidade. Para isso, regras e pressupostos que norteiam a realização da técnica devem ser respeitados a fim de contribuir com a confiabilidade e rigor dela. ${ }^{11-12}$ Com o intuito de colaborar com a utilização da entrevista discursiva, este estudo objetivou descrever uma experiência de estudo, reflexão e prática de realização da entrevista discursiva.

\section{Método}

Trata-se de um relato de experiência sobre o desenvolvimento e prática da técnica de entrevista discursiva, realizada durante a disciplina de Metodi Qualitativi per la ricerca sociale, no programa de pós-graduação em Sociologia, perfazendo um total de 72 horas, desenvolvida anualmente nos meses de setembro a dezembro. Essa disciplina é ministrada pelo coordenador do Laboratory Qualitative no Dipartimento di Culture, Politica e Società dell'Università degli Studi di Torino, na Itália. Este estudo parte da experiência de participação na disciplina, no período de setembro a dezembro de 2019, como parte do doutorado sanduíche no exterior. 
Os conteúdos abordados na disciplina abrangeram a teoria da argumentação, o desenho da pesquisa qualitativa, as técnicas de observação do participante, da entrevista discursiva e do grupo focal, a análise da documentação empírica e a escrita. Ao final do desenvolvimento dos conteúdos, foi proposta aos estudantes uma atividade avaliativa que se ocupou das seguintes temáticas: desenho ou técnicas da pesquisa qualitativa e análise dos dados mediante ao programa NVivo. Neste momento, as doutorandas optaram pelo aprimoramento direcionado à realização da entrevista discursiva, em função da aplicabilidade em suas teses, orientada nas discussões sistemáticas do roteiro, da condução da entrevista e da sua transcrição.

Considerando a origem brasileira das doutorandas, foi sugerido pelo professor da disciplina desenvolver a entrevista discursiva junto aos integrantes da associação ítalobrasileira. Os seus associados foram entrevistados mediante a utilização da amostragem valanga (técnica da bola de neve), que consiste em uma amostragem não probabilística, em que o primeiro entrevistado indica um novo participante e esse novo participante indica outro participante e assim sucessivamente, até que o objetivo proposto seja alcançado. ${ }^{13-15}$ Ou seja, os contatos são indicados por um informante-chave (privilegiado), ${ }^{16}$ baseado em suas redes de conhecimento interpessoal. ${ }^{17}$

O contato inicial se deu por telefone com o presidente da associação. Nesta ocasião foi agendada uma reunião para expor a ideia. No segundo encontro, na sede da associação, foi apresentada a atividade, os objetivos e oficializado o aceite para realizar a entrevista, que aconteceu em um terceiro encontro. Destaca-se que o segundo encontro possibilitou a elaboração da questão que nortearia as entrevistas discursivas: "Como a associação atua na integração entre as comunidades brasileira e italiana?”. Emergiram também as principais temáticas a serem tratadas nos encontros e entrevistas subsequentes, bem como a elaboração do roteiro a ser utilizado. Ressalta-se que a entrevista começa já no primeiro contato antes de ligar o gravador. ${ }^{1}$ A indicação dos demais entrevistados aconteceu a partir do primeiro entrevistado 
Técnica da entrevista discursiva em pesquisa qualitativa: relato de experiência 6

(E1). Os critérios para indicação foram: os entrevistados deveriam ser associados, ter a língua portuguesa como língua mãe e ser imigrantes brasileiros ou ítalo-brasileiros.

Devido ao tempo restrito de uma semana para a realização da atividade, foram efetuadas três entrevistas. A execução das entrevistas com as associadas aconteceu após contato telefônico para marcar dia e local apropriado. Deste modo, todas elas foram desenvolvidas na sede da associação ítalo-brasileira. A duração média foi de 53 minutos, todas tiveram o áudio gravado e transcrito na íntegra.

Fragmentos foram utilizados para ilustrar a técnica da entrevista discursiva. Antes da sua realização, o roteiro foi discutido e ajustado conforme as orientações do professor da disciplina. A experiência se deu de acordo com os seguintes temas: elaboração do roteiro, realização e transcrição das entrevistas.

Por se tratar de um exercício da disciplina, não foi necessária a aprovação de um Comitê de Ética em Pesquisa, entretanto a atividade respeitou as normas da Università degli Studi di Torino por ser um exercício da disciplina anteriormente mencionada. Destaca-se que a realização da atividade seguiu os preceitos disponibilizados na "Linee guida per l'integrità nella ricerca/2019", ${ }^{18}$ respeitando os seus princípios fundamentais: dignidade, responsabilidade, equidade, diligência e honestidade. ${ }^{9}$ Salienta-se também o respeito ao "Regolamento generale sulla protezione dei dati - Regolamento (UE) 2016/679 del Parlamento europeo e del Consiglio, del 27 aprile 2016 ” relativo à proteção das pessoas, bem como o tratamento de seus dados pessoais, compreendidos como direitos fundamentais. ${ }^{19}$ Outrossim, para garantir a manifestação e a ciência dos participantes, foi apresentado e assinado por eles em duas vias o Termo de Consentimento Livre e Esclarecido. 


\section{Resultados}

A seguir serão apresentados o roteiro, a realização e transcrição das entrevistas, bem como alguns fragmentos da entrevista, que foram transcritos de acordo com o sistema de análise das transcrições biográficas. ${ }^{1}$

\section{Roteiro}

Foi acordado que a entrevista abordaria o apoio à integração dos imigrantes brasileiros e ítalo-brasileiros na comunidade de Turim, por meio da associação ítalo-brasileira, e a partir disto houve a elaboração do roteiro, que sugere os temas a serem tratados, bem como a formulação linguística mais conveniente a ser utilizada no momento das entrevistas. ${ }^{20}$

Foram idealizados dois roteiros, os quais foram direcionados ao presidente da associação (Figura 1) e às associadas (Figura 2), com o intuito de analisar o papel da associação sob ambas as perspectivas, e, sobretudo, com o objetivo principal de aplicar a técnica da entrevista discursiva, tema deste relato de experiência.

Figura 1 - Roteiro da primeira entrevista para estudo sobre o apoio à integração dos imigrantes brasileiros e ítalo-brasileiros na cidade de Turim, 2019.

1 Ligação da história da associação com a história da sua vida. Como você chegou em Turim?

2 Quais os principais objetivos da associação? Atividades realizadas na associação.

3 Perfil das pessoas que procuram a associação.

4 Como as pessoas chegam até a associação? Quais os motivos as trazem até a associação?

5 As atividades são voltadas somente para os inscritos? Quem pode participar?

No segundo roteiro, pode-se observar o acréscimo de perguntas, que surgiram a partir da primeira entrevista e, portanto, foram introduzidas nas demais entrevistas.

Figura 2 - Roteiro das entrevistas para estudo sobre apoio à integração dos imigrantes brasileiros e ítalo-brasileiros na cidade de Turim, 2019. 
Técnica da entrevista discursiva em pesquisa qualitativa: relato de experiência $\mid 8$

1 Você pode nos contar um pouco sobre você? Como você foi a tua decisão de sair do Brasil?

2 Motivo da imigração e da escolha do país? E da cidade?

3 Antes de partir para a Itália, você se preparou de alguma maneira para sua imigração? Como você chegou até a associação?

4 Quais as principais dificuldades sentidas quanto à sua chegada na Itália? Moradia, língua, documentação, emprego?

5 Quais atividades você realiza aqui em Turim?

6 Como foi para você a experiência de vivenciar uma nova cultura?

$7 \mathrm{Em}$ termos de adoção de hábitos e costumes italianos, o quanto você já os incorporou na sua rotina?

8 Como foi a sua acolhida por parte da comunidade italiana?

$9 \mathrm{Em}$ algum momento você se sentiu discriminada pelo fato de ser imigrante? Se sim, pode nos contar o que aconteceu?

10 Você tem a intenção de retornar ao Brasil? Por quê?

11 Como você se sente em relação ao grau de pertencimento à Itália?

$12 \mathrm{O}$ que pensa sobre o papel da associação para aproximar uma interação entre comunidade brasileira e a italiana?

\section{Realização e Transcrição das Entrevistas}

Para realização das entrevistas propriamente ditas, as entrevistadoras apresentaram as perguntas quando conveniente e tinham que estar no local e na data combinados com antecedência para evitar quaisquer contratempos.

De acordo com a proposta de entrevista discursiva e transcrição ${ }^{1}$ adotada neste artigo, as entrevistas devem ser transcritas integralmente, sempre reportando as perguntas e as respostas, bem como todos os aspectos linguísticos, paralinguísticos e extralinguísticos. Desta forma, é possível identificar na transcrição as frases que foram pronunciadas de modo mais enfático ou irônico ou mais pausadamente.

A fala das entrevistadoras pode ser identificada pela escrita em negrito, ${ }^{1}$ enquanto os entrevistados serão identificados pela letra E seguidas, respectivamente, pelos números arábicos 1-2-3 para garantir o anonimato. Os "turnos" (cada linha utilizada na transcrição) de interlocução entre entrevistado e entrevistador devem ser numerados e deve haver uma linha em branco entre perguntas e respostas. Do mesmo modo, os continuadores (hum) também são considerados turnos, justificando estarem numerados. A cada nova entrevista inicia-se uma nova numeração. ${ }^{1}$ 
As vogais repetidas indicam prolongamento de um som e as reticências indicam uma pausa breve. Quando a pausa é mais longa, deve ser sinalizada entre parênteses, por exemplo: (pausa longa). Os aspectos paralinguísticos são expressos com a utilização das barras: // com a explicação entre parênteses ( ) e os aspectos extralinguísticos (choro, suspiro, tosse, gestos) com o uso dos colchetes []. Estes aspectos serão novamente abordados na discussão.

Os fragmentos ora apresentados foram intencionais para que sejam retratadas algumas características de como a transcrição deve ser realizada de acordo com o sistema de análise das transcrições biográficas. ${ }^{1}$

\section{1) Ééé qual o perfil das pessoas que procuram a associação?}

42) Então, ééé o perfil ham das pessoas que procuram a associação éee, é muito variado. Porque nós não, não fizemos. A nossa estratégia era éee hum partir do fio condutor da identidade cultural, que significa que basta ter um interesse pelo Brasil. Então ham hum esse é o perfil que une todos os nossos, as pessoas que nos procuram. Numa segunda instância o perfil varia de acordo com a atividade proposta. Então a diversidade das atividades é também uma tentativa di promover uma diversificação também pra conseguir ham ééé, envolver um número amplo di faixas de pessoas. Por exemplo: o forró é voltado para um público jovem, ééé jovens trabalhadores que acabaram de sair da universidade e que têm interesse em si de uma vida social, ativa ééé ligada com o Brasil. /Então é dança, é sensual, tem uma sociabilidade muito grande e por aí vail (fala pausadamente). Ééé crianças, senhoras de meia idade, pessoas que têm interesse, pesquisadores, pessoas que têm interesse em desenvolver um percurso social, é instituições, nós temos já algo muito próximo com o consulado do Brasil. Ééé hum, o perfil dos participantes é varia de acordo com as atividades e com aquilo que a gente tem estruturado. Então, ééé.. de zero a noventa e cinco anos, de zero até o final da vida, até depois da morte para falar a verdade. (E1)

41) Em algum momento tu te sentiu discriminada pelo fato de ser imigrante? 
42) Eu me sinto discriminada praticamente todos os dias aqui na Itália. Apesar de morar aqui ha vinte anos, mais de vinte anos, eu me sinto quase que discriminada todos os dias. Pensa que ... aqui se você imigrante // [tosse], éee eles acham que o imigrante é um pouco bobo. (E3)

55) (Segunda entrevistadora): Do ponto de vista dos italianos você acha que existe esse medo, esse preconceito, essa resistência?

56) Muito, muito, muito. Olha [limpou a garganta] eu vou dizer uma coisa pra vocês. Éee as manifestações racistas aqui na Itália acontecem todos os dias. Todos os dias, em vários níveis, pequenos, grandes. Ontem, ontem eu tava ouvindo no jornal. Vocês conhecem aquele jogador de futebol Balotelli? Mario Balotelli, que é um rapaz negro, que foi adotado, é italiano, e ele tem uma filha. E a filha dele na escola, teve uma criança que se recusou em dar a mão pra filha dele, saiu ontem no jornal isso, ontem. A criança recusou em dar a mão pra filha do Balotelli porque ela era negra. Então quer dizer isso é uma coisa que vem já de dentro de casa. (E2)

\section{1) E esses pontos que tu falou que estavam desconectados. Quais seriam eles? E tu conseguiu conectar?}

2) Então, éee hum. Os pontos que eu achava que estavam desconectados ééé hum eles são basicamente aqueles eixos que éee a gente tinha conversando. Hum (E1)

\section{3) (pausa longa)}

\section{4) [silêncio]}

5) Então quando a gente fala de eixos, a gente fala aham de campos da sociedade que eu via que a sociedade Brasile... a comunidade brasileira presente no território não tinha acesso. Não tinha éee hum, éee não tinha hum amadurecido também uma massa crítica em torno disso. Então, a única coisa eu quero lembrar é que quaando eu comecei em 2014 eu não tinha isso claro. Não era, era, para mim era um percurso de muito mais de indignação, de curiosidade, não, do que éee, do que hoje como eu vejo. Hoje eu amadureci uma massa crítica, eu consigo delinear esses pontos, eu consigo éee formular de uma forma clara. Mas na época eu não tinha isso 
claro. Então, éee eu sabia que uma associação tinha um potencial para ser muito mais do que aquilo que era, mas éee não tinha, não tinhaa é isso muito claro. Então para responder a sua pergunta eu não consegui conectar esses pontos ainda, no sentido de que éee a gente tá desenvolvendo processos para que isso aconteça éee hum, mas acredito que a gente avançou muito, noo, nos últimos anos. (E1)

\section{3) (Segunda entrevistadora): Você também se relaciona com outros imigrantes?}

44) Eu sim. Tantos. Eu faço questão de me relacionar bem, com maior gama de imigrantes possíveis. Como os marroquinos, os romenos, os africanos, eu faço parte até de uma associação africana. Porque eu acho que é importante. Nós vivemos todos juntos, num lugar onde precisamos um dos outros. (E3)

\section{5) Hum}

46) E é muito você conhecer a cultura dos outros. E eu estou tentando levar para o Brasil nesse momento um grupo, um, um professor di percussão africano, para trabalhar com as crianças nas escolas. Se vocês tiverem interessada, conhecerem alguma escola que esteja interessado eu mando o projeto para vocês. Porque é um projeto belíssimo, lindíssimo, e esse professor, ele, ele conseguiu do governo do Senegal todos os fundos, todos os custos pro projeto. É só uma escola aceita. (E3)

\section{7) Hum}

48) É muito legal. Eu acho que esse tipo de coisa tem que ser feita. Porque quanto mais você conhece, mais você respeita. (E3)

49) Hum

31) E quais são as atividades que hoje tu tem realizado aqui em Turim?

32) Atividades?(E3) 
Técnica da entrevista discursiva em pesquisa qualitativa: relato de experiência | 12

33) Isso, assim.

34) Olha, de quando eu cheguei aqui em Torino eu vou te dizer, eu fiquei muito chocada com a imagem da mulher brasileira no exterior. Ééé era uma coisa que eu nunca imaginei na minha vida, que eu, que aqui fora nós, nós ééé tivéssemos assim uma fama tão feia [fomos interrompidas por um rapaz que nos ofereceu café]. (E3)

27) Então a gente reuniu os documentos para falar: "olha declaração, estado civil em que teemm/toodaas aas mudaanças/(velocidade diminuída da fala). (E1)

69) Eu muitas vezes já me perguntei se isso tudo valia a pena. E assim, até muito recentemente eu já me perguntei isso também no sentido di falar assim: vou largar porque é muito projeto, eu tô perdido (gesticula colocando as mãos no rosto), vou afogar e vou, e não tô saindo do lugar. (E1)

\section{Discussão}

Auxiliadas pelo professor da disciplina, coube às entrevistadoras a tarefa da definição do tema principal da conversa. Este momento foi oportuno para que ambas as entrevistadoras se familiarizassem com os temas que poderiam ser abordados, evitando, assim, o comprometimento do material construído.

Para o desenvolvimento deste artigo, alguns conceitos sobre a entrevista discursiva serão apresentados ao longo da discussão, com o intuito de contextualizar a experiência em si. Designada como uma forma de relação social, um modelo característico de expressão da sociabilidade, essa técnica é o instrumento de construção de dados mais difundido no que se refere à construção da documentação empírica nas ciências sociais. ${ }^{1}$ Pode ser compreendida como uma forma específica de conversação, na qual duas ou mais pessoas se empenham em uma interação verbal com o intuito de alcançarem uma meta cognitiva estabelecida anteriormente. ${ }^{21}$ 
Além disso, proporciona aos participantes a possibilidade de construírem, com suas próprias palavras, os seus discursos. ${ }^{3}$

Dependendo das modalidades de interação entre entrevistado e entrevistador, podem-se conceber dois modelos de entrevista: a estruturada e a discursiva. Na última, a relação entre pesquisador e interlocutor se forma em um ambiente reservado e com o intuito de fornecer a aquisição de material empírico útil para responder uma pergunta específica de pesquisa. ${ }^{1}$

Neste sentido, a observação do comportamento linguístico advindo dos interlocutores é o que permitirá traçar a distinção que separa os dois tipos de entrevista. Deste modo, no momento da realização da entrevista discursiva, o entrevistado pode responder as perguntas que lhe forem dirigidas, utilizando suas próprias palavras, construindo ao seu modo a sua própria argumentação. ${ }^{3}$

A interação que ocorre entre os interlocutores é determinada nos conteúdos abordados, entretanto as modalidades nas quais a interlocução toma corpo, ou seja, tanto as palavras que apresentam as questões quanto aquelas escolhidas para que as respostas sejam articuladas, não são predeterminadas. Desta maneira, definem-se no decorrer da interação. ${ }^{1}$

Quanto às formas de interação, ora apresentadas, podem ser compreendidas como tanden, ${ }^{1,22}$ ou seja, entrevistas com uma dupla de entrevistadores. Na experiência vivenciada, o apoio da segunda entrevistadora nas três entrevistas permitiu a compreensão de vários aspectos da interação social, como exemplo, a oferta de apoio emocional e cognitivo, além de contribuir com as observações (notas de campo) pertinentes durante a interlocução. ${ }^{1}$

Salienta-se que, no momento da transcrição, as intervenções da segunda entrevistadora foram identificadas com a expressão "segundo entrevistador”, em negrito e entre parênteses. ${ }^{1} \mathrm{~A}$ entrevista discursiva pode ser compreendida como uma conversação que prevê tarefas e prerrogativas absolutamente diferentes. Desta maneira, assume duas formas: livre ou guiada. 
Técnica da entrevista discursiva em pesquisa qualitativa: relato de experiência | 14

Assim, optou-se por realizar na forma guiada (por meio de roteiro), em que há possibilidade de abordar temas sobre os quais interessam obter respostas. ${ }^{1}$

É importante apontar que, ao selecionar a forma de entrevista discursiva, esta escolha vai orientar o tipo de análise adotado e o modo de transcrição que deverá ser submetida. ${ }^{1}$ Neste sentido, com relação às entrevistas realizadas, e ora apresentadas, tinha-se a intenção de confrontar não somente as representações e os valores dos entrevistados, mas também os seus modelos argumentativos, acerca de um conjunto predefinido de temas dentre os quais se almejavam respostas. ${ }^{15}$

Neste tipo de entrevista, os entrevistados são os protagonistas da interação entre pesquisador e participante. ${ }^{23}$ Tal fato evidencia-se ao longo das entrevistas, observadas no momento da transcrição, normalmente sendo caracterizado por turnos curtos referentes às entrevistadoras e mais longos para aos entrevistados. ${ }^{1}$

Durante a elaboração do roteiro e na interlocução, um aspecto importante observado é aquele que diz respeito ao papel que o entrevistado tem na produção dos discursos. Assim lhe são atribuídos três papéis: protagonista (quando conta a história da sua vida), observador/testemunha (quando conta eventos que aconteceram/acontecem no seu contexto de vida) e especialista (quando conta eventos remotos ou futuros no espaço e/ou no tempo). ${ }^{1}$ As questões Em algum momento tu te sentiu discriminada pelo fato de ser imigrante? e Do ponto de vista dos italianos você acha que existe esse medo, esse preconceito, essa resistência? permitem atribuir dois papéis às duas entrevistadas: o de protagonista e de observador/testemunha, respectivamente.

As entrevistadoras procuraram colaborar com os entrevistados na livre construção de seus discursos. Assim, direcionavam perguntas com a finalidade de estimulá-los em direção a uma observação crítica de si mesmo e sobre o seu modo particular de agir, além de propiciar a articulação dos discursos de forma que os resultados desta análise pudessem se materializar. As 
15 | Pucci VR, Machado RA, Cardano M, Kantorski LP, Weiller TH

entrevistas foram conduzidas com a utilização das técnicas do silêncio e utilização de continuadores, que juntamente com a técnica do eco formam os três pilares para condução da entrevista discursiva. ${ }^{1}$

A técnica do eco ou técnica do espelho consiste na reprodução das últimas palavras pronunciadas pelo entrevistado, antes de ele interromper a sua fala, por um momento de embaraço, constrangimento ou inibição. Com esta técnica, o entrevistador subentende que continua escutando o seu interlocutor, deixando-o prosseguir. Quanto à técnica do silêncio, um exemplo da sua utilização pode ser verificado no excerto da entrevista realizada com E1 quando foi retomada uma questão que não tinha sido bem explorada na fala anterior e que as entrevistadoras ofertaram pausa longa e silêncio para que o entrevistado seguisse com sua narrativa.

Desta forma, o silêncio somado às expressões corporais adequadas (por exemplo: balanço da cabeça, procura do contato visual, inclinação do tronco em direção ao interlocutor) constitui a modalidade mais simples de interação, sendo conveniente recorrer a esta técnica o máximo possível. Os continuadores (hum), assim como o silêncio assinalam ao entrevistado a participação do entrevistador no seu discurso. ${ }^{1}$

Após a finalização das entrevistas, iniciou-se mais uma etapa para sua conclusão: a transcrição dos discursos construídos. As transcrições foram realizadas por uma das doutorandas, enquanto a outra ficou encarregada de fazer as revisões e colocar os textos que foram gerados dentro do sistema de análise das transcrições biográficas. ${ }^{1}$

Neste momento, foram atendidas as orientações de notação da análise das transcrições biográficas mencionadas anteriormente: sinalizar as perguntas com a utilização do negrito, colocar numeração nos "turnos" da interlocução entre entrevistador e entrevistado $(1,2,3)$, e adicionar uma linha em branco entre perguntas e respostas, além de distinguir a segunda entrevistadora (tanden). Concluídas essas atividades, deu-se o encontro com o professor da 
Técnica da entrevista discursiva em pesquisa qualitativa: relato de experiência | 16

disciplina para apreciação do material empírico produzido por meio da transcrição e para a discussão e avaliação da condução técnica da entrevista discursiva mediante a escuta dos áudios das entrevistas.

A respeito da transcrição, este momento exigiu uma escuta ativa para que o seu conteúdo fosse reproduzido fielmente. Este passo exerce a função de comunicar os aspectos do contexto da interação entre o entrevistado e o entrevistador, uma vez que os considera relacionados às dimensões linguísticas de ambos os envolvidos, além de analisar a interferência da presença ou a passagem de outras pessoas no local onde transcorre a entrevista, e que podem produzir mudanças significativas em seu enredo. ${ }^{1}$

Ao realizar a transcrição, podem ser inseridas outras informações advindas da entrevista e que são ocultas à gravação em áudio, por exemplo, quando a entrevista foi interrompida por uma pessoa de fora. Acrescenta-se ainda que quando essa atividade é realizada por quem executou a entrevista, já é possível iniciar a análise do material, dado que a transcrição é um exercício analítico pautado pelas expectativas teóricas do pesquisador e por um modelo de comunicação que não se restringe apenas às dimensões linguísticas. ${ }^{1,24}$

Acerca das modalidades de comunicação próprias do entrevistado e do entrevistador, podem-se relacioná-las a três níveis: linguístico, paralinguístico e extralinguístico. ${ }^{1}$ As palavras que compõem os trechos apresentados correspondem ao conteúdo linguístico. As locuções que o corretor ortográfico pedirá correção, como aquelas que apresentam vogais duplicadas, estão associadas à dimensão paralinguística e, neste sentido, devem ser expressas no momento da transcrição. ${ }^{1}$

A observação da dimensão extralinguística diz respeito às observações que extrapolam a comunicação verbal e o significado das palavras, por exemplo, a velocidade da fala [velocidade diminuída da fala], gestos e expressões corporais [coloca as mãos no rosto]. A dimensão 
extralinguística foi registrada em notas de campo durante as entrevistas e acrescida na transcrição.

As notas de campo enriquecem as transcrições e podem ser feitas durante a entrevista ou logo após a sua realização. Neste exercício, optou-se por realizar as notas de campo durante a interação entre elas e os interlocutores. As transcrições foram realizadas logo após o encerramento das entrevistas e passaram por conferência de fidedignidade, que corresponde à conferência do áudio acompanhada do texto transcrito em mãos, o que permitiu corrigir equívocos nas entrevistas subsequentes, como exemplo, evitar a realização de mais de uma pergunta ao mesmo tempo, reavaliar os rumos da investigação, entre outros.

A transcrição deve estar alicerçada dentro de um procedimento metodológico escolhido pelo pesquisador, uma vez que não há uma regra universal para realizar essa atividade o que a torna uma tarefa eclética, variada. Entretanto, ao mesmo tempo, exige dos pesquisadores compreensão para que estabeleçam e assumam um conjunto de princípios e práticas no intuito de harmonizar tais transcrições. ${ }^{24}$

Transcrever as entrevistas exigiu das entrevistadoras comprometimento de recursos temporais, físicos e humanos. Embora a média das entrevistas tenha sido de 53 minutos, a transcrição detalhada do que foi dito e a inserção das notas de campo compreendeu um tempo médio de oito horas. Durante esse exercício, foi possível reconhecer a importância de realizar uma transcrição de qualidade, uma vez que a análise do material empírico já se inicia durante esse processo. ${ }^{25-26}$

A interferência de outras pessoas durante as entrevistas e o uso de dois idiomas pelos entrevistados (apesar de as entrevistas terem sido realizadas em português, dois dos três entrevistados, usavam palavras em italiano com frequência) foram os desafios enfrentados durante a transcrição. 
Técnica da entrevista discursiva em pesquisa qualitativa: relato de experiência | 18

\section{Conclusão}

Essa forma específica de conversação, quando utilizada em pesquisas qualitativas, deve ser orientada por critérios rigorosos com o intuito de atribuir confiabilidade e rigor. Essa técnica permite aos entrevistadores a organização do roteiro de acordo com o tema a ser investigado que pode ser adaptado no decorrer das entrevistas, quanto à forma e ao tempo, porém sem perder o foco do objetivo principal.

A técnica da entrevista discursiva não predetermina resposta certa ou errada. Além disso, oportuniza aos entrevistados um importante lugar de fala. Guiados pelas entrevistadoras, os participantes tiveram a possibilidade de desenvolver um olhar analítico e reflexivo acerca do tema.

A utilização dessa técnica exigiu um preparo teórico e prático na construção dos dados empíricos. A transcrição demandou escuta ativa dos áudios das entrevistas e conhecimento aprofundado do guia metodológico. Neste sentido, participar da disciplina contribuiu para compreender os seus pressupostos e experimentar a sua condução.

\section{Referências}

1. Cardano M. Manual de pesquisa qualitativa: a contribuição da teoria da argumentação. Petrópolis: Vozes; 2017.

2. Cardano M. Defending qualitative research: design, analysis, and textualization. Londres: Routledge; 2020.

3. Cardano M. O problema da invisibilidade e a eloquência das pequenas coisas: reflexões sobre os pontos fortes da pesquisa qualitativa. Rev Gaúcha Enferm. 2018;39:e82654. doi: https://doi.org/10.1590/1983-1447.2018.82654

4. Goffman E. Sul “fieldwork”. Studi Culturali. 2006;3(1):103-15.

5. Augusto CA, Souza JP, Dellagnelo EHL, Cario SAF. Pesquisa qualitativa: rigor metodológico no tratamento da teoria dos custos de transação em artigos apresentados nos congressos da Sober (20072011). Rev Econ Sociol Rural. 2013;51(4):745-64. doi: http://dx.doi.org/10.1590/S0103-20032013000400007 
6. Silva A, Castro-Silva CR, Moura L. Pesquisa qualitativa em saúde: percursos e percalços da formação para pesquisadores iniciantes. Saúde Soc. 2018;27(2):632-45. doi: https://doi.org/10.1590/s010412902018172700

7. Creswell J. Qualitative inquiry and research design: choosing among five approaches. 3rd ed. Thousand Oaks: Sage Publications; 2013.

8. Silverman D. Doing qualitative research: a practical handbook. Londres: Sage Publications; 2013.

9. Hughes EC. Lo sguardo sociologico. Bolonha: Il Mulino; 2010.

10. Ravagnoli NCSR. A entrevista narrativa como instrumento na investigação de fenômenos sociais na Linguística Aplicada. The Espec. 2018;39(3):1-14. doi: https://doi.org/10.23925/2318-7115.2018v39i3a2

11. Kapp S. Entrevistas na pesquisa sócio-espacial. Rev Bras Estud Urbanos Reg. 2020;22(e202006):1-32. doi: https://doi.org/10.22296/2317-1529.rbeur.202006

12. Barreto MS, Nascimento DG, Magini LYZ, Oliveira IL, Vieira VCL, Marcon SS. Discourse of nurses and doctors on the use of the emergency service by immigrants. Esc Anna Nery. 2019;23(3): e20190003. doi: https://doi.org/10.1590/2177-9465-ean-2019-0003

13. Ferrari F, Montermini C, Ghirotto L, Mainini C, Fugazzaro S, Costi S. Partecipare ad uno studio riabilitativo di ricerca per pazienti con NSCLC: GT sul processo psico-sociale alla base delle motivazioni, 2017. In: Therapeutic exercise: foundations, evidences, clinical reasoning in physiotherapy practice; 2017 ott 12-13; Roma. Modena: University of Modena and Reggio Emilia; 2017 [citato 2020 sett 23]. Disponibile da: https://iris.unimore.it/handle/11380/1169505\#.X6vVxx3Q9Ms

14. Riva C, Boato A. Il fandom delle serie tv e l'esperienza dello shipping. Mediascapes J [Internet]. 2020 [citato 2020 sett 23];14:35-48. Disponibile da: https://statusquaestionis.uniroma1.it/index.php/mediascapes/article/view/16599

15. Meo A, Moiso V. Giovani italiani: autonomamente dipendenti e debolmente inclusi. Riv Politi Soc [Internet]. 2020 [citato 2020 sett 23];2:109. Disponibile da: https://www.ediesseonline.it/wpcontent/uploads/2020/07/RPS_2-2020.pdf\#page=109

16. Sredanovic D, Della Puppa F. Aspettative, immaginari e progettualità di mobilità e stanzialità nel quadro della Brexit: cittadini dalla nascita e "naturalizzati". Polis. 2020;1:85-108. doi: 10.1424/96441

17. Camoletto RF, Scarvada A. Il cibo come specchio: la costruzione delle maschilità tra adolescenti e giovani uomini. AG AboutGender. 2020;9(17):97-141. doi: https://doi.org/10.15167/22795057/AG2020.9.17.1161

18. Ethics: Commissione per l'Etica e l'Integrità nella Ricerca (IT). Linee guida per l'integrità nella ricerca [Internet]. 2019 [citato 2020 febbr 14]. Disponibile da: 
http://www.ibb.cnr.it/img/CNR_Ethics,_Linee_guida_per_l'integrita_nella_Ricerca,_revisione_2019_ee5c e7.pdf

19. Garante per la Protezione dei Dati Personali. Regolamento generale sulla protezione dei dati: regolamento (UE) 2016/679 del Parlamento europeo e del Consiglio del 27 aprile 2016 [Internet]. 2016 [citato 2020 febbr 14]. Disponibile da: https://www.garanteprivacy.it/documents/10160/0/Regolamento+UE+2016+679.+Arricchito+con+riferimen ti+ai+Considerando+Aggiornato+alle+rettifiche+pubblicate+sulla+Gazzetta+Ufficiale++dell\%27Unione+e uropea $+127+$ del $+23+$ maggio +2018

20. Cardano M. Tecniche di recerca qualitativa: percorsi di ricerca nelle scienze sociali. Roma: Coracci; 2013.

21. Cardano M. L’intervista discorsiva. In: Cardano M, Ortalda F. Metodologia della ricerca psicosociale. Milan: UTET Università; 2017. p. 209.

22. Fideli R, Marradi A. Enciclopedia delle Scienze Sociali. Roma: Istituto dell'Enciclopedia Italiana; 1996. p. 71-82.

23. Gofman E. Il rituale dell'interazione. Bologna: Il Mulino; 1988.

24. Azevedo V, Carvalho M, Fernandes-Costa F, Mesquita S, Soares J, Teixeira F, et al. Transcrever entrevistas: questões conceptuais, orientações práticas e desafios. Referência. 2017;4(14):159-68. doi: https://doi.org/10.12707/RIV17018

25. Bastos LC, Biar LA. Análise de narrativa e práticas de entendimento da vida social. DELTA Doc Estud Linguíst Teór Apl. 2015;3(N Esp):97-126. doi: https://doi.org/10.1590/0102-445083363903760077

26. Silva CC, Borges FT. Análise Temática Dialógica como método de análise de dados verbais em pesquisa qualitativa. Linhas Críticas [Internet]. 2017 [acesso em 2020 set 23];23(51):245-67. Disponível em: https://periodicos.unb.br/index.php/linhascriticas/article/view/8221

Editora Científica Chefe: Cristiane Cardoso de Paula Editora associada: Alexa Pupiara Flores Coelho

Agradecimento: Ao Instituto Federal de Educação, Ciência e Tecnologia do Rio Grande do Sul (IFRS) pela liberação de Roberta Antunes Machado para cursar o seu doutoramento.

\section{Autor correspondente}

Vanessa Rodrigues Pucci

E-mail: vanessarpucci@hotmail.com

Endereço: Centro de Ciências da Saúde - CCS. Avenida Roraima, 100, prédio 26, sala 1302, Camobi, Santa Maria, RS. 
21 | Pucci VR, Machado RA, Cardano M, Kantorski LP, Weiller TH

CEP: 97105900

\section{Contribuições de Autoria}

\section{1 - Vanessa Rodrigues Pucci}

Desenho do manuscrito; coleta, análise, interpretação dos dados; redação científica e revisão final do manuscrito.

\section{2 - Roberta Machado Antunes}

Desenho do manuscrito; coleta, análise, interpretação dos dados; redação científica e revisão final do manuscrito.

\section{3 - Mario Cardano}

Orientação na construção do manuscrito; análise dos dados; revisão crítica do manuscrito.

\section{4 - Luciane Prado Kantorski}

Orientação na construção do manuscrito; redação científica; revisão crítica do manuscrito.

\section{5 - Teresinha Heck Weiller}

Revisão crítica do manuscrito

\section{Como citar este artigo}

Pucci VR, Machado RA, Cardano M, Kantorski LP, Weiller TH. Técnica da entrevista discursiva em pesquisa qualitativa: relato de experiência. Rev. Enferm. UFSM. 2020 [Acesso em: Anos Mês Dia]; vol.10 e97: 1-21. DOI:https://doi.org/10.5902/2179769241680 